\title{
Effects of boats on the surface and acoustic behaviour of an endangered population of bottlenose dolphins
}

\author{
M. Guerra*, S. M. Dawson, T. E. Brough, W. J. Rayment \\ Department of Marine Science, University of Otago, Dunedin 9016, New Zealand
}

\begin{abstract}
Coastal cetaceans are increasingly being exposed to boats and noise as nature tourism grows. Such activity has a wide range of detrimental effects on the surface behaviour of cetaceans, but effects on their acoustic behaviour are poorly understood. We quantified the effects of tour boats and of the observing research boat on the group structure and vocal behaviour of bottlenose dolphins Tursiops truncatus in Doubtful Sound, New Zealand. Acoustic recordings and group follow data were collected from a $5 \mathrm{~m}$ research vessel, and analysed via an informationtheoretic approach. Groups with mother-calf pairs were significantly less cohesive and coordinated when tour boats were audible. They were more vocal when boats were close and while moving away, presumably to re-establish group structure. Furthermore, groups with calves increased their whistle rates when tour boats were travelling faster, while groups without calves became quieter. Dolphins also responded to boat noise with alterations in whistle frequency and duration. These findings suggest that elevated boat noise affects communication, and groups with calves are particularly sensitive to boat presence and noise. Group structure and whistle parameters were affected by the research boat, highlighting the importance of accounting for observer effects in studies of tourism impacts. The particular sensitivity of groups with calves to boats has important implications for the management of impacts on this population due to its endangered status and history of low calf survival.
\end{abstract}

KEY WORDS: Dolphin-watching - Tourism - Boat noise - Tursiops truncatus - Behaviour Communication

Resale or republication not permitted without written consent of the publisher

\section{INTRODUCTION}

In the last 2 decades there has been a rapid growth of tourism targeting coastal populations of cetaceans, raising concern about the potential impact of vessel traffic and boat approaches. This has prompted a scientific response to assess the effect of tour boats and boat noise on wild populations, as well as the creation of legislative and management frameworks aimed at achieving sustainability (Higham \& Lück 2007). A wide range of reactions to tour boats has been demonstrated, including longer diving times, erratic behaviour, increased swimming speeds, decreased time spent foraging, resting and/or socialis- ing, and changes in vocal behaviour (Nowacek et al. 2001, Williams et al. 2002, Lusseau 2003a, Buckstaff 2004, Lemon et al. 2006, Miller et al. 2008, Stamation et al. 2010, Steckenreuter et al. 2012). Longer-term effects, such as changes in residency patterns (Lusseau 2005) and declines in relative abundance (Bejder et al. 2006), have also been detected. Measuring these effects is necessary for appropriate management and conservation of these species.

Most studies examining the effects of boats on whales and dolphins have quantified short-term changes in surface behaviour, frequently measured as changes in group activity (e.g. Lusseau 2003a, Williams et al. 2006, Christiansen et al. 2010), respira- 
tion or diving patterns (e.g. Miller et al. 2008, Stamation et al. 2010) and movement patterns (e.g. Nowacek et al. 2001, Stensland \& Berggren 2007, Schaffar et al. 2013). Although several studies have investigated the effects of boats and associated noise on the animals' acoustic behaviour, this aspect of behavioural response and its implications still remain poorly understood. Understanding how boat noise affects dolphins' acoustic abilities is of obvious importance, as dolphins depend on acoustic signals for communication, navigation, foraging and detecting predators (Wells \& Scott 1999, Tyack \& Clark 2000). For example, whistles are used as contact calls to maintain mother-calf cohesion and group coordination (Caldwell et al. 1990, Smolker et al. 1993, Janik \& Slater 1998). Vessel noise often overlaps with the frequency bands dolphins use for communication, potentially masking vocalisations and impairing communication among group members (Richardson \& Malme 1995, Jensen et al. 2009). Dolphins have been shown to increase their whistle rate as a response to boat presence (Scarpaci et al. 2000, Buckstaff 2004), with stronger responses in the presence of calves (Van Parijs \& Corkeron 2001a). Several studies have described increases in the frequency and/or sound level of vocalisations when vessel noise is louder, in different species of whales (Lesage et al. 1999, Scheifele et al. 2005, Parks et al. 2007) and in dolphins (La Manna et al. 2013), suggesting that calls are modified to compensate for masking effects.

Although the majority of studies on the impacts of tour boats on cetaceans are carried out from an observing vessel, very few studies have quantitatively addressed the effects of the research boat itself (see Lusseau 2003b, 2006, Richter et al. 2006 for exceptions). Quantifying the impact of the research vessel is crucial to account for potentially confounding observer effects and to minimise bias. For instance, if a tour boat approaches a group of dolphins whose natural behaviour has already been changed by the presence of a research boat, having measured the extent to which the research boat affects the dolphins' behaviour will help separate confounding effects from the measured response to the tour boat. In addition, if the animals' behaviour is already altered, their reaction to the subsequent arrival of a tour boat may not reflect their response to the boat if they had been previously undisturbed, potentially underestimating the effect of the tour boat. For example, Richter et al.'s (2006) study of the effects of tourism on sperm whales Physeter macrocephalus found that the presence of the research boat caused changes in the whales' mean blow intervals. The inclusion of this factor to account for variability of behaviour allowed for a more accurate measure of the effects of other boats.

Doubtful Sound (Fiordland, New Zealand; Fig. 1) is home to a small $(\mathrm{N}=60, \mathrm{CV}=0.5 \%)$, endangered population of bottlenose dolphins Tursiops truncatus (Currey et al. 2009b). Aside from occasional extrafiord excursions (Henderson et al. 2013), the dolphins are resident within the fiord year-round and appear to form a largely closed population (Currey et al. 2009b). Scenic cruises run year-round in the fiord, with the highest frequency in spring and summer. Although no tour boats specifically target the dolphins, dolphins are an iconic feature of the environment for the tourism industry and interactions between dolphins and boats have been of concern (Lusseau 2003a,b, 2006). Previous studies showed that the presence of boats decreased the amount of time dolphins spent socialising and resting and increased diving intervals (Lusseau 2003a,b). Energetic costs of avoidance strategies were predicted to be higher for females than for males (Lusseau 2003b). The New Zealand Department of Conservation implemented a voluntary code of conduct in 2008 to mitigate the potential impacts, establishing guidelines to leave dolphin encounters to chance (i.e. dolphin-boat interactions may only take place if the dolphins are on the vessel's intended path or if the dolphins approach the boat), and restricting vessel traffic in areas considered to be critical habitat.

This study was designed to quantify the effects of tour boats and the research vessel on the communication and surface behaviour of bottlenose dolphins in Doubtful Sound. In line with the impacts on behaviour observed in other dolphin populations, we posed the following questions: (1) Do tour boats affect the cohesion and movement patterns of dolphin groups? (2) How do tour boats affect whistle rates, and do boat speed and closest distance of approach influence the dolphins' response? (3) Do dolphins modify whistle frequency and/or duration as a response to vessel noise? (4) How does the research vessel affect the dolphins' acoustic and surface behaviour? (5) Are groups with calves more sensitive to vessels?

\section{MATERIALS AND METHODS}

\section{Field techniques and data collection}

This study was carried out in Doubtful Sound $\left(45^{\circ} 20^{\prime} \mathrm{S}, 167^{\circ} 00^{\prime} \mathrm{E}\right)$ from a $5 \mathrm{~m}$ aluminium-hulled research vessel (RV 'Nemo', hereafter RV) powered 


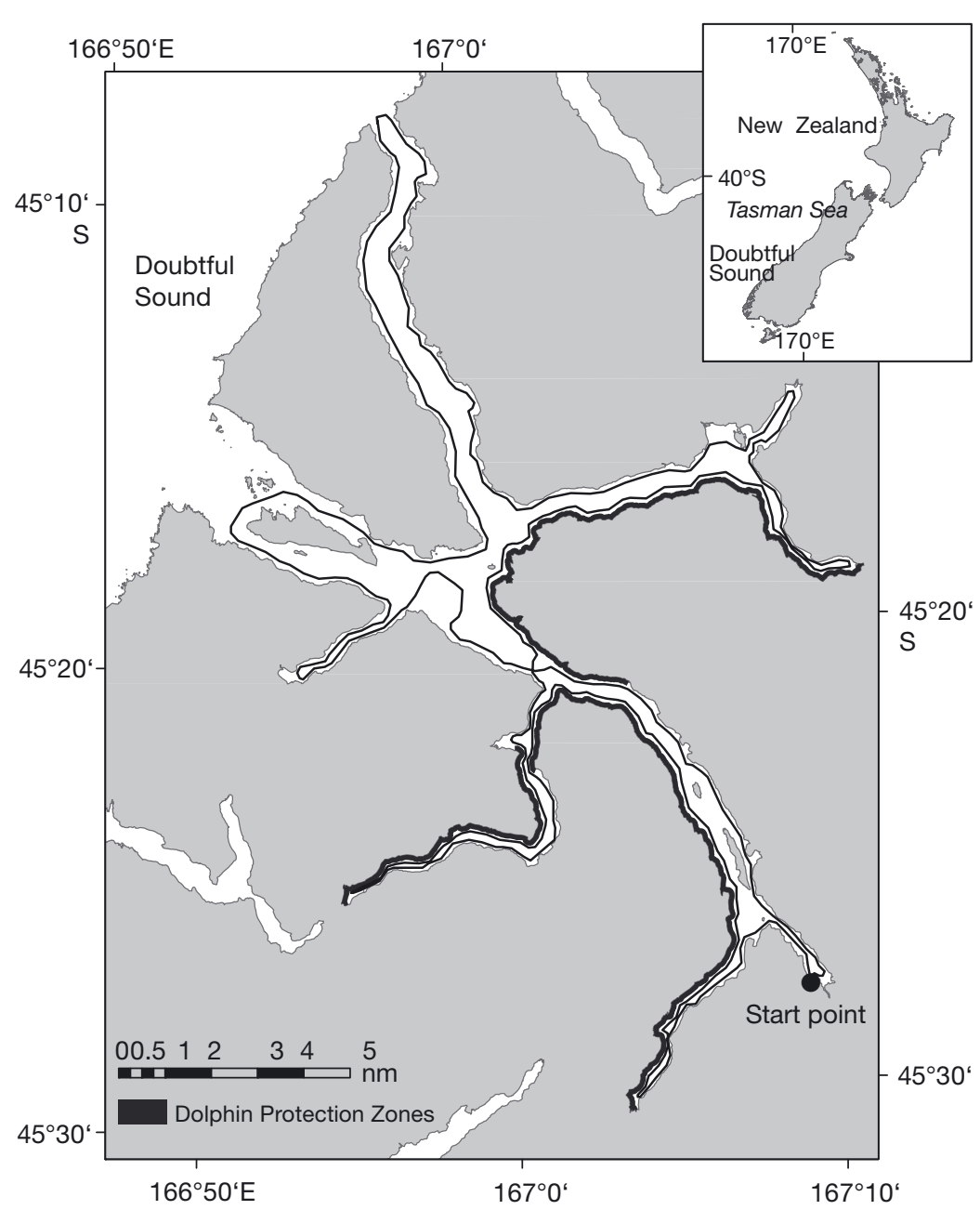

Fig. 1. Doubtful Sound, New Zealand, with Dolphin Protection Zones and standardised survey route (thin black line). From the start point, surveys typically followed the west shore and continued along the indicated path

off between lowest possible intrusiveness and obtaining reliable behavioural observations. This procedure is similar to a regressive technique employed in previous studies with the same dolphin population (Lusseau 2003b), and is useful when a true control (i.e. no research boat) is not possible (Morrison et al. 2001, Lusseau 2003b). The SA was maintained while the dolphin group interacted with other boats, and was terminated at the end of the protocol or when weather conditions deteriorated (Beaufort sea state $>3$ ). A group was defined as an aggregation of dolphins in which the members were scattered over less than $1 \mathrm{~km}^{2}$ and were headed in the same general direction (Schneider et al. 1998).

Dolphin groups in Doubtful Sound are almost continuously travelling (M. Guerra \& S. Dawson unpubl. data), and there is no evidence of individuals favouring particular areas within the fiord; therefore, it was unlikely that there would be significant bias in the individuals likely to be sampled (i.e. being followed in a SA). During the study period, individuals in the population had similar sampling probabilities (mean sampling rate per day, $\bar{x}=$ $0.51, \mathrm{SD}=0.09$; per survey trip [defined as a number of days, often consecutive, which were closely grouped in time and ranged from 7 to $15 \mathrm{~d}$ ]: $\bar{x}=$

by a 4 -stroke $70 \mathrm{hp}$ outboard engine. Systematic surveys of the Doubtful Sound complex were conducted daily from December 2011 to November 2012, following a pre-determined route developed by Schneider (1999), which was consistently followed in the same direction and covered the entire fiord area to locate any persistently isolated groups (Fig. 1).

On finding a bottlenose dolphin group, the RV commenced a standardised $2 \mathrm{~h}$ long 'staged approach' (SA), in which dolphin behaviour was recorded for set periods of time and from particular distances as the encounter progressed (Table 1). The SA was designed to quantify the potential impact of the RV's approach on the dolphins by studying the group's reactions to RV proximity and whether the RV was in an approaching or retreating stage. The furthest observation distance $(200 \mathrm{~m})$ reflects a trade-
0.92, SD = 0.07). Composition of encountered groups typically changed from one day to another, with group size averaging 22 dolphins (SD = 11.6).

The RV stages in the SA were divided into $5 \mathrm{~min}$ samples to collect data on group composition, group

Table 1. Phases of the staged approach (abbreviations in parentheses) carried out by the research vessel to record bottlenose dolphin (Tursiops truncatus) behaviour

\begin{tabular}{|lrc|}
\hline Stage & $\begin{array}{c}\text { Time } \\
\text { (min) }\end{array}$ & $\begin{array}{c}\text { Approx. distance } \\
\text { from dolphins (m) }\end{array}$ \\
\hline $200 \mathrm{~m}$, 'approach' (200A) & $0-20$ & 200 \\
$100 \mathrm{~m}$, 'approach' (100A) & $20-40$ & 100 \\
$20 \mathrm{~m}$, 'close range' (20C) & $40-80$ & $<20$ \\
$100 \mathrm{~m}$, 'retreat' (100R) & $80-100$ & 100 \\
$200 \mathrm{~m}$, 'retreat' (200R) & $100-120$ & 200 \\
\hline
\end{tabular}


size, general behaviour state and boat presence. Data were recorded via a GPS-interfaced palmtop computer (HP 200LX) running a programme specifically written for this study. Group composition was recorded as presence or absence of calves, determined by visual observations and later confirmed via photo-identification (see Currey et al. 2007 for methodology). All individuals within the group were photographed and subsequently identified to obtain group size. This is possible in this population, as all individuals are photographically identifiable (Currey et al. 2007). Calves ( $<1$ yr old) were defined as individuals $<1 / 2$ the length of an adult, with visible foetal fold marks, and swimming in close association with a female. Behaviour state was defined as the predominant activity of $>50 \%$ of the group (Lusseau 2003a, Williams et al. 2006, Lundquist et al. 2012). This was determined by scan sampling (Altmann 1974) and characterised as 1 of 6 states: travelling, milling, resting, diving, socialising, or actively interacting with boats (Table 2).

For the purposes of our analysis, vessels other than the RV were classified as 'tour boats', which included commercial tour vessels up to $38 \mathrm{~m}$ in length and recreational vessels. Situations in which a tour boat was within $200 \mathrm{~m}$ of the dolphins were defined as dolphin-boat interactions (hereafter, interactions). This cut-off distance was chosen to match the maximum distance used in the SA. Measures of distance (in metres) were visually estimated, with laser rangefinder assistance (Bushnell Yardage Pro Compact $600)$. This means that laser rangefinder measurements of larger or more reflective targets, judged to be approximately the same distance away as the target of interest, were used to guide the visual estimation of distance. Speed of tour boats and dolphins (in knots) were estimated in comparison with RV speed, which was measured and displayed via GPS (updated less than every $1 \mathrm{~s}$ ). To minimize inconsistency, the same observer carried out distance and speed estimations throughout the study, and was previously trained by estimating known distances inside the fiord. In addition, during observations, the RV was driven in a consistent orientation to the dolphins, by following them from behind and to the side in a direction parallel to the group's heading, increasing the consistency in angle of observation. Although some imprecision associated with speed and distance estimates was unavoidable, we have no evidence of bias.

\section{Data collection - movement patterns}

At the start of each 5 min sample, 4 variables describing the movement patterns of the observed group of dolphins were recorded:

(1) Group spread area; calculated from the estimated distance between the 2 dolphins furthest apart in the group ( $a$ ) and the estimated distance perpendicular to this across the group centre $(b)$. The minimum elliptical area (in $\mathrm{m}^{2}$ ) enclosing the group was thus estimated as $\Pi(a / 2)(b / 2)$

(2) Coordination or consistency of orientation among group members; recorded via visual estimates of the largest fraction of the group $(1=0-25 \%$, $2=26-50 \%, 3=51-75 \%, 4=76-100 \%)$ moving in the same direction $\left(<90^{\circ}\right.$ difference)

(3) Group speed; estimated in comparison to RV speed, in knots

(4) Direction of travel; estimated via hand-held compass, in degrees.

Table 2. Definitions of behavioural states of bottlenose dolphin (Tursiops truncatus) groups, adapted from Lusseau (2003a)

\begin{tabular}{|ll}
\hline Behaviour states (code) & Definition \\
\hline Diving (DIV) & $\begin{array}{l}\text { Direction of movement varies; individuals dive synchronously for long intervals and } \\
\text { perform steep dives (arching their backs at the surface); group spacing varies }\end{array}$ \\
Milling (MIL) & $\begin{array}{l}\text { Little or no net movement; low coordination in orientation (individuals surface facing } \\
\text { different directions); short dive intervals; individuals relatively loosely grouped }\end{array}$ \\
Resting (REST) & $\begin{array}{l}\text { Group moves slowly in a constant direction ( } \leq 2 \text { knots), swimming with short, relatively } \\
\text { constant, synchronous dive intervals; individuals tightly grouped }\end{array}$ \\
Socialising (SOC) & $\begin{array}{l}\text { Diverse interactive behavioural events observed, such as sexual, inter-individual inter- } \\
\text { actions and aerial behaviours; dive intervals vary; group spacing varies } \\
\text { Group moves steadily in a constant direction (>2 knots), swimming with short, relatively } \\
\text { constant dive intervals; group spacing varies }\end{array}$ \\
Interacting with boat (INTR) & $\begin{array}{l}\text { Group closely approaches boat; dolphin-boat interactive behavioural events observed, } \\
\text { such as bow-riding and stern wake-riding }\end{array}$ \\
\hline
\end{tabular}




\section{Underwater acoustic recording system}

Acoustic recordings were made throughout the SA, as long as there was no heavy rain (to avoid irregular background noise levels). Continuous recordings were made via a stereo-hydrophone array custombuilt specifically for this study, towed behind the RV on a $50 \mathrm{~m}$ cable. The 2 hydrophone elements were separated by $5 \mathrm{~m}$, and each was recorded on a separate channel of the recorder. Each hydrophone node contained a $40 \mathrm{~dB}$ pre-amplifier with a $3 \mathrm{~dB} /$ octave high-pass filter (corner frequency: $3.39 \mathrm{kHz}$ ) to reduce low-frequency engine and flow noise. While this particular array was not calibrated, an array with the same hydrophone elements, amplifiers and construction methods had best sensitivity at $16 \mathrm{kHz}$ $(-162 \mathrm{~dB}-\mathrm{V} / \mu \mathrm{Pa})$ and a frequency response of 5 to $40 \mathrm{kHz}( \pm 3.5 \mathrm{~dB}$ ) (Barlow et al. 2008). Output from the array was continuously recorded with an Edirol R44 digital recorder, which recorded WAV files (sampling frequency $=48.0 \mathrm{kHz}, 16 \mathrm{bit}$ ) to a flash-card. While acoustic recordings were underway, the speed and distance (to the dolphins) of any tour boats in the area were noted, including the distance at closest approach to the dolphin group. When possible, we aimed to position the RV so that it would not be closer to the tour boat than the dolphins were, to ensure that the hydrophone array did not receive louder noise levels from tour boats than the dolphins did and to minimise potential masking of dolphin vocalisations by boat noise.

\section{Data analysis}

Analysis of movement patterns

Depending on the presence of tour boats, the $5 \mathrm{~min}$ samples of the SA were classified as 'Control' (RV only) or 'Interaction' (RV plus other boats). In addition, 2 samples (5 min each) were defined as 'Before' (before the arrival of a tour boat) and 2 were defined as 'After' (after its departure). All samples spanned 5 min, except 'Interaction' and the last of the 'Before' samples, which depended on the times of arrival and/or departure of tour boats.

Using the observations at the start of each $5 \mathrm{~min}$ sample, 4 response variables were obtained for each sample: group density, group coordination, group speed and heading change. Group density (number of dolphins per $100 \mathrm{~m}^{2}$ ) was estimated by dividing the number of dolphins in the group by the elliptical spread area ([group size/spread area] × 100). Head- ing change was calculated as the absolute difference between the group's direction of travel at the start of 2 consecutive samples.

\section{Acoustic analysis}

Acoustic recordings were reviewed using Audacity 1.3 Beta. For encounters in which tour boats had come within audible range of the dolphins, 5 acoustic samples were extracted for analysis. A boat was assumed to be within hearing range of the dolphins if it was audible in the recording to a human listener. Samples included: Inaudible-Before (tour boat not audible, $10 \mathrm{~min}$ before it became audible), AudibleBefore (boat audible, from the moment it became audible until it reached a distance $200 \mathrm{~m}$ from the dolphin group, or its distance at closest approach), 'Interaction' (boat audible, within $200 \mathrm{~m}$ of the group), Audible-After (from the point of leaving a distance of $200 \mathrm{~m}$, or the boat's distance at closest approach, until it became inaudible) and Inaudible-After (boat not audible, 10 min after the tour boat ceased to be audible). If tour boats did not come within $200 \mathrm{~m}$ of the dolphins, there would be no 'Interaction' phase, and the Audible-After would follow straight after the Audible-Before phase, using the time of closest approach as the transition point. Control data (i.e. no tour boats, only RV) were obtained by extracting $10 \mathrm{~min}$ samples, termed Inaudible-Control, from each RV stage in which no tour boats had been previously audible or seen. One Inaudible-Control sample was randomly selected from each available stage of each SA.

How, and at what received levels, dolphins first perceive noise from approaching tour boats is unknown in this study, and arguably unknowable. For that reason we used audibility to a human listener as a proxy for audibility to dolphins. Human hearing is more sensitive at low frequencies than dolphin hearing ( $\mathrm{Au}$ 1993). This was partially compensated for by the $3 \mathrm{~dB} /$ octave filtration in our hydrophones, which ensured $10 \mathrm{~dB}$ of attenuation at $1 \mathrm{kHz}(-15$ at $500 \mathrm{~Hz}$ ). However, hearing sensitivities measured directly in different media may not relate straightforwardly to levels as perceived by a human via a hydrophone and recorder. The fact that the hydrophones were up to $250 \mathrm{~m}$ away from the dolphin group (including the $200 \mathrm{~m}$ RV-dolphin separation and the $50 \mathrm{~m}$ array cable) may have resulted in some bias in the length of the 'Audible-Before' and 'Audible-After' samples. For instance, if a tour boat approached the dolphins from the side opposite of 
the RV's location, the received level at the dolphin's location was higher than at our hydrophones, due to propagation losses. Nevertheless, on average, the time for which boat noise is audible to a human listener is a reasonable proxy for that received by the dolphins.

Acoustic samples were imported into Raven Pro 1.4 for analysis of whistle parameters and rates. All sound samples were viewed as spectrograms (512point FFT, Hamming window, analysing filter bandwidth: $122 \mathrm{~Hz}, 69.9 \%$ overlap, frequency range: 0 to $20000 \mathrm{~Hz}$ ). Vocalisations were deemed suitable for analysis if they were audible and clearly visible in the spectrogram (e.g. Fig. 2).

The standardised rate of whistle production was calculated by dividing the number of whistles in each sample by sample duration and number of dolphins present (whistles per minute per dolphin). Whistle rates were matched to data on behaviour state, RV stage and calf presence. If acoustic samples covered more than 1 behaviour state or RV stage, a whistle rate was obtained for each sample and each of the 2 sub-samples was weighted by its proportional duration. Dolphin whistles were quantified using whistle duration (s), lower and upper frequencies $(\mathrm{kHz})$, and peak frequency (frequency at which the maximum amplitude occurred, kHz) (Fig. 2). These 4 acoustic parameters were analysed separately. Since the aim of these analyses was to investigate potential modifications in whistle properties as a reaction to vessel noise, the factors describing tour boat and RV scenarios did not use a 'before/after' specification. In-

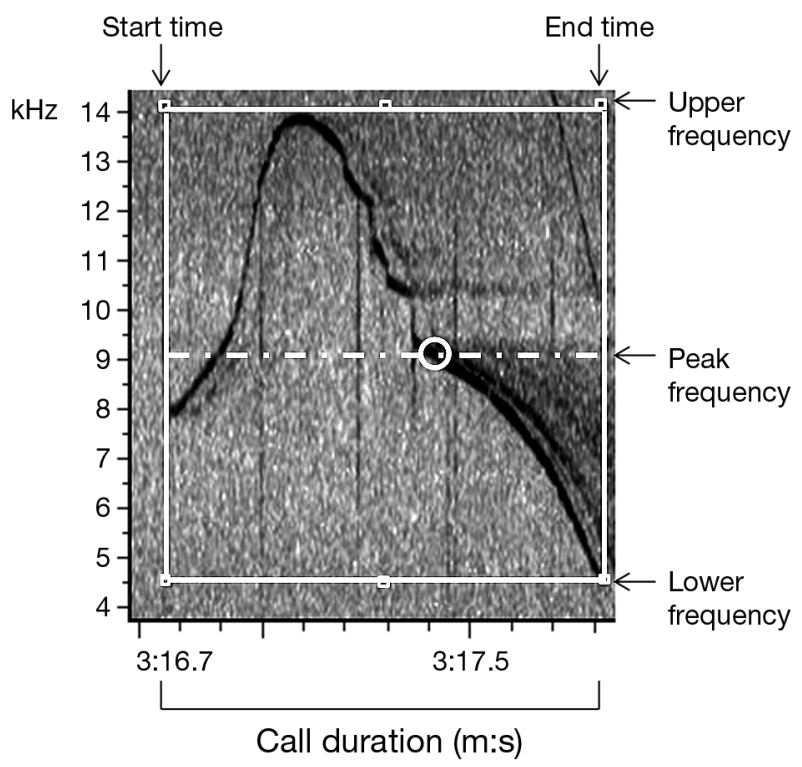

Fig. 2. Acoustic parameters used to quantify bottlenose dolphin (Tursiops truncatus) whistles stead, tour boats were classified as not audible, audible at $>200 \mathrm{~m}$, or audible at $<200 \mathrm{~m}$; and the RV included 200, 100, or $20 \mathrm{~m}$ stages.

\section{Statistical analysis}

An information-theoretic approach (Burnham \& Anderson 2002, Anderson 2008) was used to quantify the effect of boats on the dolphins' acoustic behaviour, group cohesion and movement patterns. This approach is naturally suited to impact studies (e.g. Lusseau 2003b, Richter et al. 2006, Currey et al. 2009b), and is particularly useful for behavioural ecology studies with multiple explanatory variables (Johnson \& Omland 2004, Garamszegi 2011, Richards et al. 2011).

Acoustic and movement pattern data were modelled to take into account the tour boat scenario (presence/absence and before/during/after effects of tour boats), stage of the RV (during the SA), presence or absence of calves, and behaviour state (Table 3). Behaviour state was included to (1) account for a presumably important source of variability in movement pattern data, since it was evident that different behavioural activities would result in different group structures and movements; and (2) to investigate the influence of behaviour on vocalisation rates and avoid confounding effects, since whistling rate of dolphins is influenced by behavioural context (Herzing 1996, Van Parijs \& Corkeron 2001b, Hernandez et al. 2010). Models also included interaction terms between (1) calf presence and tour boat scenario, (2) calf presence and RV stage, and (3) tour boat scenario and RV (only in the case of movement pattern analyses). Inclusion of additional parameters in the models (such as season, time of day, group size, or other interaction terms) was not possible due to paucity of data. However, the effect of group size on each behavioural response (including all movement patterns and whistle rates) was investigated through simple regression analyses, showing weak correlations $\left(\mathrm{R}^{2}=0\right.$ to 0.03$)$. Cumulative effects of consecutive dolphin-boat interactions are possible but could not be tested for due to the small sample size of interactions.

Competing models were ranked with Akaike's information criterion (AICc; Akaike 1973, Burnham et al. 2011). Model-averaged coefficients (i.e. estimates of the regression coefficients) were calculated to represent the magnitude and direction of the effect of each factor on the response variables (Burnham \& Anderson 2002, Nakagawa \& Freckleton 2011, 
Table 3. Information on models used in the Akaike's information criterion (AIC) analyses for the model-selection process. TB: tour boat scenario; RV: research vessel stage; beh: behaviour state; calf: calf presence; TBspeed: tour boat speed; DCA: distance of tour boat's closest approach to dolphins; LMM: linear mixed models; CLMM: cumulative link mixed models. All models include the random effect of group.

\begin{tabular}{|c|c|c|c|}
\hline Response variables & $\begin{array}{c}\text { Model } \\
\text { type }\end{array}$ & Most complex model in set & $\begin{array}{l}\text { of models } \\
\text { tested }\end{array}$ \\
\hline \multicolumn{4}{|c|}{ Surface behaviour - movement patterns } \\
\hline Group speed & LMM & Speed $\sim \mathrm{TB}+\mathrm{RV}+$ beh + calf + TB:calf + RV:calf $+\mathrm{TB}: \mathrm{RV}$ & 128 \\
\hline Heading change & LMM & Heading $\Delta \sim \mathrm{TB}+\mathrm{RV}+$ beh + calf $+\mathrm{TB}:$ calf $+\mathrm{RV}:$ calf $+\mathrm{TB}: \mathrm{RV}$ & 128 \\
\hline Group density & LMM & Density $\sim \mathrm{TB}+\mathrm{RV}+$ beh + calf $+\mathrm{TB}:$ calf $+\mathrm{RV}:$ calf $+\mathrm{TB}: \mathrm{RV}$ & 128 \\
\hline Group coordination & CLMM & Coordination $\sim \mathrm{TB}+\mathrm{RV}+$ beh + calf + TB:calf + RV:calf $+\mathrm{TB}: \mathrm{RV}$ & 128 \\
\hline \multicolumn{4}{|c|}{ Acoustic behaviour - whistle rates } \\
\hline Whistle rate & LMM & Whistle rate $\sim \mathrm{TB}+\mathrm{RV}+$ beh + calf $+\mathrm{TB}:$ calf $+\mathrm{RV}$ : calf & 64 \\
\hline $\begin{array}{l}\text { Whistle rate - audible } \\
\text { samples only }\end{array}$ & LMM & $\begin{array}{l}\text { Whistle rate } \sim \text { TB }+ \text { TBspeed }+ \text { DCA }+ \text { beh }+ \text { calf }+ \\
\text { TB:calf }+ \text { TBspeed:calf }+ \text { DCA:calf }\end{array}$ & 256 \\
\hline \multicolumn{4}{|c|}{ Acoustic behaviour - whistle parameters } \\
\hline Whistle duration & LMM & Duration $\sim \mathrm{TB}+\mathrm{RV}+$ beh + calf $+\mathrm{TB}$ :calf $+\mathrm{RV}$ :calf & 64 \\
\hline Whistle upper frequency & LMM & Upper freq. $\sim \mathrm{TB}+\mathrm{RV}+$ beh + calf $+\mathrm{TB}:$ calf $+\mathrm{RV}$ :calf & 64 \\
\hline Whistle lower frequency & LMM & Lower freq. $\sim \mathrm{TB}+\mathrm{RV}+$ beh + calf $+\mathrm{TB}:$ calf $+\mathrm{RV}$ :calf & 64 \\
\hline Whistle peak frequency & LMM & Peak freq. $\sim \mathrm{TB}+\mathrm{RV}+$ beh + calf $+\mathrm{TB}:$ calf $+\mathrm{RV}$ :calf & 64 \\
\hline
\end{tabular}

Symonds \& Moussalli 2011). Models with $\triangle$ AIC values $<7$ were included in model-averaging (Burnham et al. 2011). Error estimates were calculated as unconditional standard errors (SE), which incorporate sampling variance and model selection uncertainty (Burnham \& Anderson 2002). Approximate $95 \%$ CIs were calculated as $1.96 \times$ SE. Due to most explanatory variables being categorical, parameter estimates in the model outputs are given relative to reference categories. The following reference categories were stipulated: 'control' for the tour boat scenario (i.e. no tour boats present in the case of movement pattern analyses; no tour boats present or audible in the case of acoustic analyses), '200A' for the RV stage, 'travelling' for the behaviour variable and 'absence' for the calf variable. The behaviour state of travelling was selected as a reference because it was the most commonly observed behaviour ( $70 \%$ of samples).

Data on whistle rates and whistle parameters, and log-transformed data on group speed, changes in direction of travel and group density were fitted with linear mixed models (LMM; McCulloch et al. 2008). The most complex model in each set was tested for model assumptions using diagnostic plots. Data on whistle parameters satisfied all model assumptions. Data on whistle rates, group speed, changes in direction of travel and group density satisfied assumptions of normality of residuals and linearity, but there was some evidence for heteroscedasticity, which LMM may not fully account for; therefore, the confidence intervals associated with the model-averaged regres- sion estimates may be conservative. Group coordination was an ordinal variable - with 4 categories of increasing proportion of the group facing the same direction - and was therefore analysed with ordinal regression analysis by using cumulative link mixed models (CLMM; Agresti 2002). Models were fitted via maximum likelihood estimation. Mixed models were chosen in all analyses to take into account random effects derived from repeated measures of each group of dolphins within and among SAs, since group composition was different in every encounter, and therefore account for autocorrelation. A new 'group' was assigned to each SA, and also if a group joined or split during a SA. This was true for all models, including those used in the analysis of whistle parameters, in which case whistles could not be assigned to individuals, so 'group' was the smallest unit of identity to control for repeated measures. All statistical analyses were done in the software programme R (V 2.15.1; R Core Team 2012).

\section{RESULTS}

\section{Research effort}

Research effort comprised $492 \mathrm{~h}$ (79 d) on the water, of which $174 \mathrm{~h}$ were spent in the presence of dolphins. A total of 60 SAs were achieved, recording a total of $123.2 \mathrm{~h}$ of data on group cohesion and movement patterns. Thirty-four of the SAs were recorded 
acoustically, resulting in a total of $71.7 \mathrm{~h}$ of acoustic data. During the SAs, a total of 35 dolphin-vessel interactions were monitored (in which a tour boat was within $200 \mathrm{~m}$ of the dolphins); of these interactions 17 were acoustically recorded. Interactions ranged from $30 \mathrm{~s}$ to $16.2 \mathrm{~min}$ and averaged $4.4 \mathrm{~min}(95 \% \mathrm{CI}=3.4$ to 5.4). There were no interactions with $>1$ tour boat at a time. Acoustic data were obtained for an additional 12 'acoustic-only interactions', in which tour boats were presumed to be within hearing range of the dolphins but not within $200 \mathrm{~m}$ of them.

\section{Effects of vessels on movement patterns}

A total of 1251 samples on movement patterns were collected during staged approaches. Potential correlation among the 4 response variables quantifying movement patterns was investigated via linear regression. Since correlation coefficients were low (i.e. $\mathrm{r}^{2}$ values between 0 and 0.16 ), variables were analysed independently for ease of interpretation. Data on group speed, heading change, density and coordination were fitted to models and analysed in 4 separate model-selection processes (Table 4).

As expected, behaviour state had a strong effect on all movement patterns (Fig. 3a-d). Model-averaged estimates indicated that diving, milling and socialising groups were slower, less coordinated and had more pronounced changes in direction of travel than groups that were travelling. Milling groups were also more spread out than other groups.

Model-averaged estimates of the effect of tour boat scenario on group speed (i.e. before, during and after dolphin-boat interactions, compared to absence of tour boats) were of small magnitude and with confidence intervals overlapping zero (Fig. 3a), suggesting that tour boats caused no significant effects on speed. RV effects on speed were small compared to the effect of behavioural state, with dolphins reducing their speed in the retreating stages of the SA when calves were present, as shown by the negative (and significantly different from zero) estimates for 'calf:RV.100R' and 'calf:RV.200R' (Fig. 3a). The effect of tour boats and the RV on heading change of dolphin groups was subtle (Fig. 3b). Heading change was influenced only when dolphin groups were actively interacting with a tour boat (with more pronounced changes in direction) or during the RV's $200 \mathrm{~m}$ retreat stage in the absence of calves (with smaller changes).

While compactness and coordination of groups without calves was unaffected by tour boats, groups with calves were considerably more spread out before, during and after interactions with tour boats (compared to the control scenario) (Fig. 3c), and were less coordinated during and after interactions (Fig. 3d). Regarding the effect of the RV, groups with calves were more cohesive (i.e. more tightly grouped and coordinated) at the start of the encounter than groups without calves. During the close-range and retreat stages, however, groups with calves decreased their cohesion, while groups without calves increased it.

\section{Effects of vessels on whistle rates}

A total of 160 samples were extracted from the 34 acoustic recordings (Table 5). As we only obtained 1 sample during resting behaviour and 2 during active interaction with tour boats, these 3 samples were excluded from the analysis. Mean whistle rate (whistles per minute per dolphin) was 0.14 (range $=0$ to $1.49,95 \% \mathrm{CI}=0.10$ to 0.18 ).

Model selection indicated that behaviour state was the strongest predictor of whistle rate (Table 4), and that tour boats had some influence, while the RV had a very weak effect. Model-averaged estimates indicated that whistle rate was significantly higher in groups whose predominant activity was milling or, especially, socialising, than in travelling groups (Fig. 4a). Groups without calves were essentially unaffected by the passage of tour boats, whereas groups with calves had significantly higher whistle rates when tour boats were audible within $200 \mathrm{~m}$ of the dolphins (compared to the control scenario) and even higher rates after the boat's closest approach.

\section{Effect of tour boat attributes on whistle rate}

A second analysis included the estimated tour boat speed and the distance of closest approach (DCA) to the dolphins. Boat speed was used as a proxy for noise, as most noise from propeller-driven boats comes from cavitation, which typically increases with speed (Arveson \& Vendittis 2000, Buckstaff 2004, Jensen et al. 2009). Boat speed and DCA were available for 75 samples (tour boat speed: $\bar{x}=10$ knots, range $=0$ to 30 knots; DCA: $\bar{x}=306 \mathrm{~m}$, range $=1$ to $1000 \mathrm{~m})$. Since the RV had no detectable effect on whistle rate (Fig. 4a), to simplify the analysis it was not included in the models. Input variables were standardised using Gelman's (2008) approach, to 
Table 4. Model-selection analysis. Models are ranked from best to worst using $\triangle \mathrm{AICc}$ scores. Only the top ranked models $(\triangle \mathrm{AICc}<7)$ are shown. Multiplication signs indicate interaction. All models included the random effect of 'group'. N: sample size (in parentheses); df: degrees of freedom; logLik: log likelihood; $\Delta$ AICc: difference in AICc score between $i^{\text {th }}$ model and best model in set; $w_{i}$ : Akaike weight; acc. $w_{i}$ : accumulated weight; $L_{i}$ : model likelihood given the data; freq.: frequency; beh: behaviour state of dolphin group; RV: research vessel stage; TB: tour boat scenario; calf: calves; TBspeed: tour boat speed; DCA: closest distance of tour boat when approching dolphins; Grp: group

\begin{tabular}{|c|c|c|c|c|c|c|c|c|}
\hline \multirow{2}{*}{$\begin{array}{l}\text { Response } \\
\text { variable (N) } \\
\text { Grp speed (1249) }\end{array}$} & \multicolumn{2}{|c|}{ Model } & \multirow{2}{*}{$\begin{array}{l}\mathrm{df} \\
17\end{array}$} & \multirow{2}{*}{$\begin{array}{c}\text { logLik } \\
263.8\end{array}$} & \multirow{2}{*}{$\begin{array}{c}\Delta \mathrm{AICc} \\
0.00\end{array}$} & \multirow{2}{*}{$\begin{array}{c}W_{i} \\
0.74\end{array}$} & \multirow{2}{*}{$\begin{array}{c}\text { acc. } w_{i} \\
0.74\end{array}$} & \multirow{2}{*}{$\begin{array}{c}L_{i} \\
1.00\end{array}$} \\
\hline & 1 & beh $+\mathrm{RV} \times$ calf & & & & & & \\
\hline & 2 & beh $+\mathrm{TB}+\mathrm{RV} \times$ calf & 20 & 265.7 & 2.38 & 0.23 & 0.97 & 0.30 \\
\hline & 3 & beh $+\mathrm{TB} \times$ calf $+\mathrm{RV} \times$ calf & 23 & 266.6 & 6.80 & 0.03 & 0.99 & 0.03 \\
\hline \multirow{5}{*}{$\begin{array}{l}\text { Heading change } \\
\text { (1219) }\end{array}$} & 1 & $\mathrm{beh}+\mathrm{RV}$ & 12 & -1961.4 & 0.00 & 0.61 & 0.61 & 1.00 \\
\hline & 2 & beh + RV + calf & 13 & -1961.3 & 1.86 & 0.24 & 0.85 & 0.39 \\
\hline & 3 & beh + TB + RV & 15 & -1961.0 & 5.35 & 0.04 & 0.89 & 0.07 \\
\hline & 4 & beh & 8 & -1968.4 & 5.93 & 0.03 & 0.92 & 0.05 \\
\hline & 5 & beh $+\mathrm{RV} \times$ calf & 17 & -1959.3 & 6.08 & 0.03 & 0.95 & 0.05 \\
\hline \multirow[t]{2}{*}{ Grp density (1242) } & 1 & beh $+\mathrm{TB} \times$ calf $+\mathrm{RV} \times$ calf & 23 & -1147.4 & 0.00 & 0.68 & 0.68 & 1.00 \\
\hline & 2 & $\mathrm{~TB} \times$ calf $+\mathrm{RV} \times$ calf & 18 & -1153.3 & 1.48 & 0.32 & 1.00 & 0.48 \\
\hline Grp coordination (1245) & 1 & beh $+\mathrm{TB} \times$ calf $+\mathrm{RV} \times$ calf & 23 & -1017.5 & 0.00 & 0.99 & 0.99 & 1.00 \\
\hline \multirow[t]{7}{*}{ Whistle rate (157) } & 1 & beh $+\mathrm{TB}$ & 11 & 51.7 & 0.00 & 0.34 & 0.34 & 1.00 \\
\hline & 2 & beh & 6 & 46.0 & 0.01 & 0.34 & 0.68 & 1.00 \\
\hline & 3 & beh + calf & 7 & 46.1 & 2.06 & 0.12 & 0.80 & 0.36 \\
\hline & 4 & beh $+\mathrm{TB}+$ calf & 12 & 51.7 & 2.17 & 0.12 & 0.92 & 0.34 \\
\hline & 5 & beh $+\mathrm{TB} \times$ calf & 17 & 56.8 & 4.23 & 0.04 & 0.96 & 0.12 \\
\hline & 6 & beh + RV + TB & 15 & 53.4 & 6.02 & 0.02 & 0.97 & 0.05 \\
\hline & 7 & beh + RV & 10 & 47.2 & 6.56 & 0.01 & 0.99 & 0.04 \\
\hline \multirow{10}{*}{$\begin{array}{l}\text { Whistle rate - audible } \\
\text { samples only (75) }\end{array}$} & 1 & beh + TB $\times$ calf + TBspeed $\times$ calf & 13 & 35.0 & 0.00 & 0.45 & 0.45 & 1.00 \\
\hline & 2 & beh + TB + TBspeed $\times$ calf & 11 & 30.7 & 2.68 & 0.12 & 0.57 & 0.26 \\
\hline & 3 & beh $+\mathrm{TB} \times$ calf + TBspeed $\times$ calf + DCA & 14 & 35.0 & 3.01 & 0.10 & 0.67 & 0.22 \\
\hline & 4 & beh + TB & 8 & 25.9 & 4.33 & 0.05 & 0.72 & 0.11 \\
\hline & 5 & beh + TB + calf & 9 & 27.0 & 4.75 & 0.04 & 0.77 & 0.09 \\
\hline & 6 & beh + TB + TBspeed $\times$ calf + DCA & 12 & 31.0 & 4.99 & 0.04 & 0.80 & 0.08 \\
\hline & 7 & beh $+\mathrm{TB}+$ TBspeed & 9 & 26.6 & 5.49 & 0.03 & 0.83 & 0.06 \\
\hline & 8 & $\begin{array}{l}\text { beh }+ \text { TB } \times \text { calf }+ \text { TBspeed } \times \text { calf }+ \\
\text { DCA } \times \text { calf }\end{array}$ & 15 & 35.2 & 5.77 & 0.03 & 0.86 & 0.06 \\
\hline & 9 & beh + TB + DCA + calf & 10 & 27.4 & 6.54 & 0.02 & 0.87 & 0.04 \\
\hline & 10 & beh + TB + TBspeed + calf & 10 & 27.4 & 6.58 & 0.02 & 0.89 & 0.04 \\
\hline \multirow[t]{5}{*}{ Whistle duration (3583) } & 1 & $\mathrm{~TB} \times$ calf $+\mathrm{RV}$ & 10 & -2645.0 & 0.00 & 0.71 & 0.71 & 1.00 \\
\hline & 2 & $\mathrm{~TB} \times$ calf $+\mathrm{RV} \times$ calf & 12 & -2645.0 & 3.95 & 0.10 & 0.81 & 0.14 \\
\hline & 3 & RV & 5 & -2652.6 & 5.00 & 0.06 & 0.87 & 0.08 \\
\hline & 4 & beh $+\mathrm{TB} \times$ calf $+\mathrm{RV}$ & 13 & -2644.6 & 5.09 & 0.06 & 0.92 & 0.08 \\
\hline & 5 & $\mathrm{RV} \times$ calf & 6 & -2652.5 & 6.99 & 0.02 & 0.94 & 0.03 \\
\hline \multirow{3}{*}{$\begin{array}{l}\text { Whistle lower freq. } \\
\text { (3583) }\end{array}$} & 1 & $\mathrm{~TB} \times$ calf $+\mathrm{RV} \times$ calf & 12 & -8342.8 & 0.00 & 0.64 & 0.64 & 1.00 \\
\hline & 2 & $\mathrm{~TB} \times$ calf $+\mathrm{RV}$ & 10 & -8345.5 & 1.47 & 0.31 & 0.94 & 0.48 \\
\hline & 3 & beh $+\mathrm{TB} \times$ calf $+\mathrm{RV} \times$ calf & 15 & -8342.6 & 5.67 & 0.04 & 0.98 & 0.06 \\
\hline \multirow{3}{*}{$\begin{array}{l}\text { Whistle upper freq. } \\
\text { (3583) }\end{array}$} & 1 & beh $+\mathrm{TB} \times$ calf $+\mathrm{RV} \times$ calf & 15 & -9798.6 & 0.00 & 0.53 & 0.53 & 1.00 \\
\hline & 2 & beh $+\mathrm{TB} \times$ calf $+\mathrm{RV}$ & 13 & -9800.8 & 0.45 & 0.42 & 0.96 & 0.80 \\
\hline & 3 & beh $+\mathrm{TB} \times$ calf & 11 & -9805.1 & 5.12 & 0.04 & 1.00 & 0.08 \\
\hline \multirow{2}{*}{$\begin{array}{l}\text { Whistle peak freq. } \\
\text { (1600) }\end{array}$} & 1 & beh $+\mathrm{TB} \times$ calf $+\mathrm{RV}$ & 13 & -3969.8 & 0.00 & 0.74 & 0.74 & 1.00 \\
\hline & 2 & beh $+\mathrm{TB} \times$ calf $+\mathrm{RV} \times$ calf & 15 & -3968.8 & 2.20 & 0.25 & 0.99 & 0.33 \\
\hline
\end{tabular}

obtain parameter estimates of numerical variables (i.e. DCA and speed) on a comparable scale (Grueber et al. 2011).

In the model-selection process, tour boat speed in relation to calves was included in the 3 best models, and thus was considered to be a good predictor of whistle rate (Table 4). Model-averaged estimates suggest that DCA did not influence whistle rate, but boat speed had a strong effect, particularly on groups with calves (Fig. 4b). While groups without calves decreased their whistle rate when tour boat speed was higher, groups with calves reacted in the opposite way, by increasing their whistle rate when tour boats were faster. 

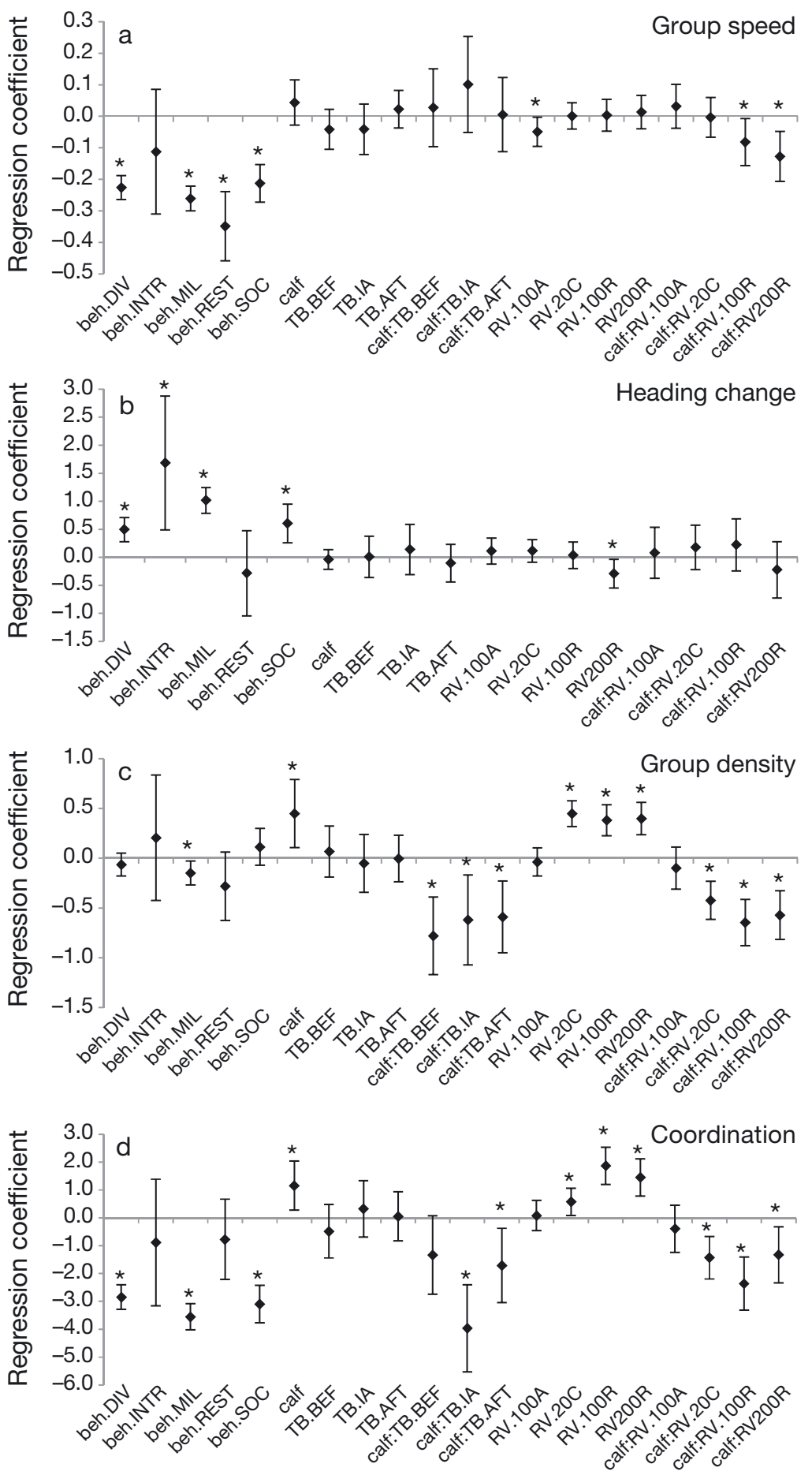

Fig. 3. Model-averaged estimates for the analyses of movement patterns of bottlenose dolphins Tursiops truncatus. Response variables are (a) group speed, (b) heading change, (c) group density and (d) group coordination. Points are regression coefficients; error bars are $95 \% \mathrm{CI}_{\text {; }}$ asterisks indicate significant effects. Reference categories are no TB, beh. travelling, no calves, RV.200A. Abbreviations as follows: beh $=$ behaviour state (DIV = diving, INTR = actively interacting with boats, MIL = milling, REST $=$ resting, $\mathrm{SOC}=$ socialising); $\mathrm{TB}=$ tour boat scenario $(\mathrm{IA}=$ interaction, $\mathrm{BEF}=$ before IA, AFT = after IA $)$, RV = research vessel stage $(100 \mathrm{~A}, 20 \mathrm{C}, 100 \mathrm{R}, 200 \mathrm{R}$; see Table 1 for further information); calf = calves present

\section{Effects of vessels on whistle parameters}

A total of 3583 whistles were quantified. Measurements of whistle duration $(\mathrm{s})$, lower and upper frequencies $(\mathrm{kHz})$, and peak frequency $(\mathrm{kHz})$ were analysed in 4 separate model-selection processes. Peak frequency could not be detected in whistles that overlapped with other calls of higher maximum amplitudes (including burst pulses and echolocation clicks), resulting in a smaller sample size $(\mathrm{N}=1600)$.

Model selection indicated that the effects of tour boats and the RV in relation to calf presence were important predictors of all measured whistle parameters (Table 4). Model-averaged estimates showed that tour boats and the RV affected the duration and frequency characteristics of whistles, and that groups with and without calves responded differently to vessel noise (Table 6, Fig. 5a-d). In the absence of calves, all significant reactions in whistle frequency to situations with increased noise levels (whether caused by tour boats or the RV) involved a shift to lower frequency bands. When calves were present, however, increased boat noise resulted in whistles shifting to higher frequencies. Groups with calves produced longer whistles when tour boats were within $200 \mathrm{~m}$ of the dolphins, whereas groups without calves produced shorter ones (compared to situations in which tour boats were not audible). Only groups without calves showed changes in whistle duration in response to RV proximity, producing shorter whistles during the 100 and $20 \mathrm{~m}$ stages than at $200 \mathrm{~m}$. The strongest changes in whistle duration and frequency were caused by the presence of tour boats. Differences caused by behaviour state were not significant, except for a decreased peak frequency in whistles of diving groups (Fig. 5b).

\section{DISCUSSION}

This study showed that tour boats and the research vessel affected the vocal behaviour and group cohesion of an endan- 
Table 5. Summary of acoustic data used for analysis of vocal behaviour of bottlenose dolphins Tursiops truncatus in Doubtful Sound. TB: tour boat; RV: research vessel; c.a.: closest approach; N: sample size; dur.: sample duration

\begin{tabular}{|lcrrr|}
\hline Tour boat scenario & Abbreviation & $\mathrm{n}$ & $\begin{array}{c}\text { Mean dur. } \\
\text { (min) }\end{array}$ & $\begin{array}{c}\text { Total } \\
\text { dur. (h) }\end{array}$ \\
\hline TB inaudible (RV only) & NAUDctrl & 4 & 10.00 & 7.83 \\
TB inaudible at $>200$ m before c.a. & NAUDbef & 19 & 7.39 & 2.34 \\
TB audible at $>200$ m before c.a. & AUDbef & 31 & 8.40 & 4.34 \\
TB audible at $<200$ m ('interaction') & AUDia & 17 & 3.59 & 1.02 \\
TB audible at $>200$ m after c.a. & AUDaft & 29 & 7.15 & 3.45 \\
TB inaudible at $>200$ m after c.a. & NAUDaft & 17 & 8.33 & 2.36 \\
Total no. of samples & - & 160 & - & 21.34 \\
\hline
\end{tabular}

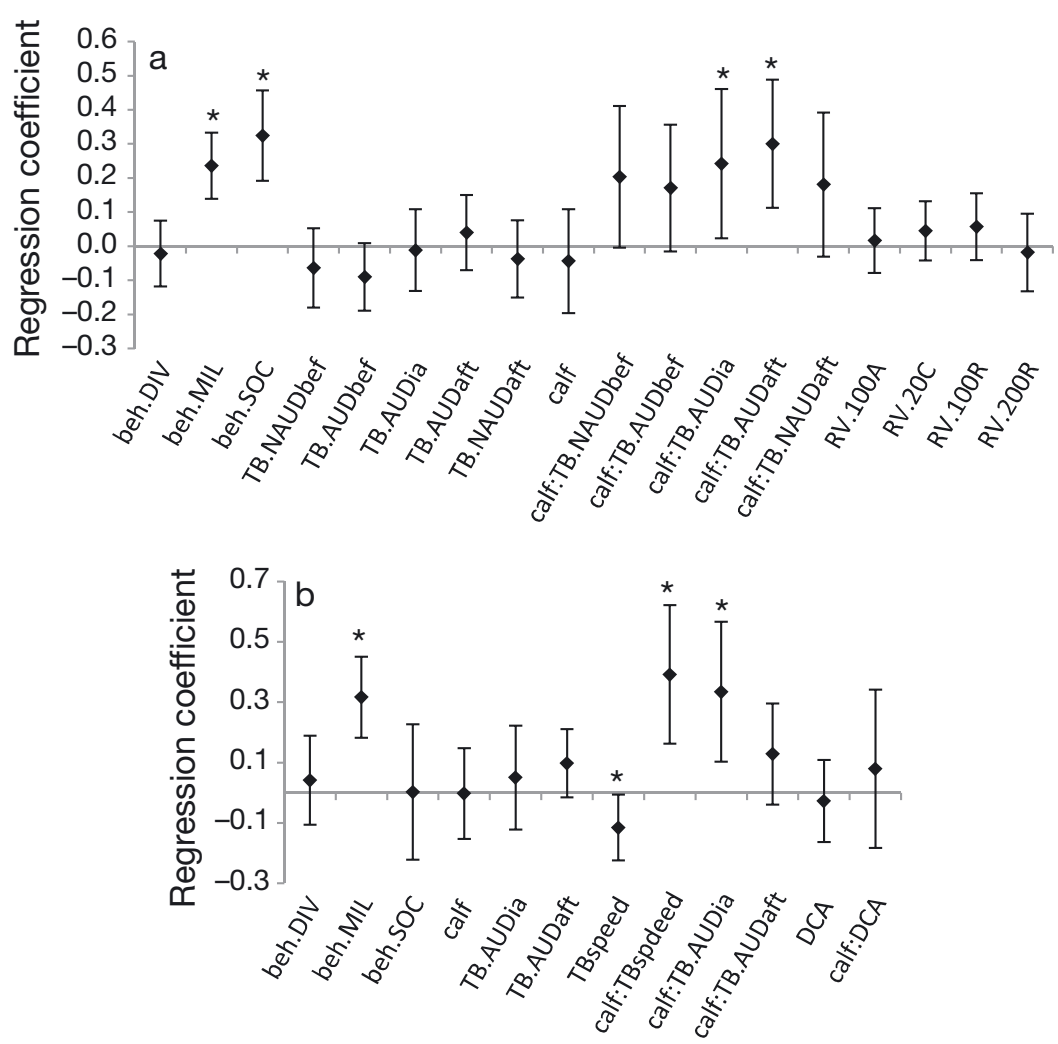

Fig. 4. Model-averaged estimates for the analyses of whistle rates of bottlenose dolphins Tursiops truncatus using (a) all samples, and (b) 'tour boat audible' samples only. Points are regression coefficients; error bars are $95 \% \mathrm{CI}_{\text {; }}$ asterisks indicate significant effects. Reference categories for (a) are no TB, beh. travelling, no calves, RV.200A, and for (b) TB.AUDbef, beh. travelling, no calves. Abbreviations are as follows: beh = behaviour state (DIV = diving, $\mathrm{MIL}$ $=$ milling, $\mathrm{SOC}=$ socialising $) ; \mathrm{TB}=$ tour boat $(\mathrm{NAUD}=\mathrm{TB}$ not audible, $\mathrm{AUD}=$ TB audible, ia $=$ interactions, bef/aft $=$ before/after closest approach); calf $=$ calves present; RV = research vessel stage $(100 \mathrm{~A}, 20 \mathrm{C}, 100 \mathrm{R}, 200 \mathrm{R})$; TBspeed $=$ speed of TB. DCA = closest distance of TB when approaching dolphins by mother-calf separation events or altered group structure (Scarpaci et al. 2000, Van Parijs \& Corkeron 2001a). Our study is the first to demonstrate a simultaneous occurrence of elevated whistle rates and decreased group cohesion as a reaction to boats. Increased whistle rates and whistle modifications recorded in groups with calves when boats are nearby may help compensate for the masking effects of boat noise and restore group cohesion after the passage of a boat.

\section{Effects of tour boats on group behaviour}

Tour boats had a considerable effect on group cohesion: while groups without calves seemed unaffected by tour boats, groups with calves were substantially more spread out before, during and after interactions, and were also less coordinated in their orientation during and after interactions. These effects were likely mediated acoustically, as the response occurred after tour boats became clearly audible but before they reached the dolphins' proximity. Although we could not quantify movement patterns of particular individuals, mother-calf pairs were sometimes seen to move away from approaching tour boats, increasing their distance from the rest of the group and reducing the proportion of the group oriented in the same direction. The effect of tour boats on group cohesion is thus likely to reflect a separation of mother-calf pairs from the rest of the group.

Error associated with distance estimates (and therefore spread area) may have resulted in lower precision of density estimates for dolphin groups. In spite of this, models including a tour gered population of bottlenose dolphins. Groups with mother-calf pairs were particularly sensitive to boat presence and noise, being less cohesive in the proximity of tour boats. Studies that have found an increase in dolphins' whistling rate in response to a boat's passage have suggested that this could be triggered boat and research boat effect (as interaction terms with calf presence) were clearly supported, with these models adding to a weight of $100 \%$ (Table 4). This suggests that in spite of the potential low precision, the discussed effects are real, and findings, reliable. 
Table 6. Summary of the effects of vessel noise on whistle parameters of bottlenose dolphins Tursiops truncatus. The direction of the effect is represented for significant model-averaged coefficients only ( $\uparrow$ :positive effect; $\downarrow$ : negative effect; $\approx:$ no significant change). Detailed estimates are shown in Fig. 5. Reference category: no TB, RV.200m, no calves. TB: tour boat; (AUD: audible

$<200 \mathrm{~m}$ from dolphins; IA: audible <200 m from dolphins); RV: distance of research vessel from dolphins $(200,100$, or 20 m)

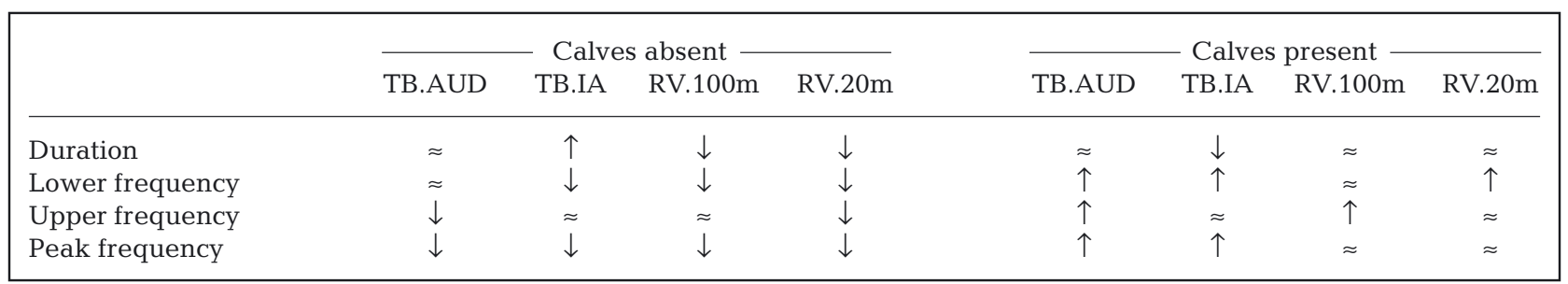
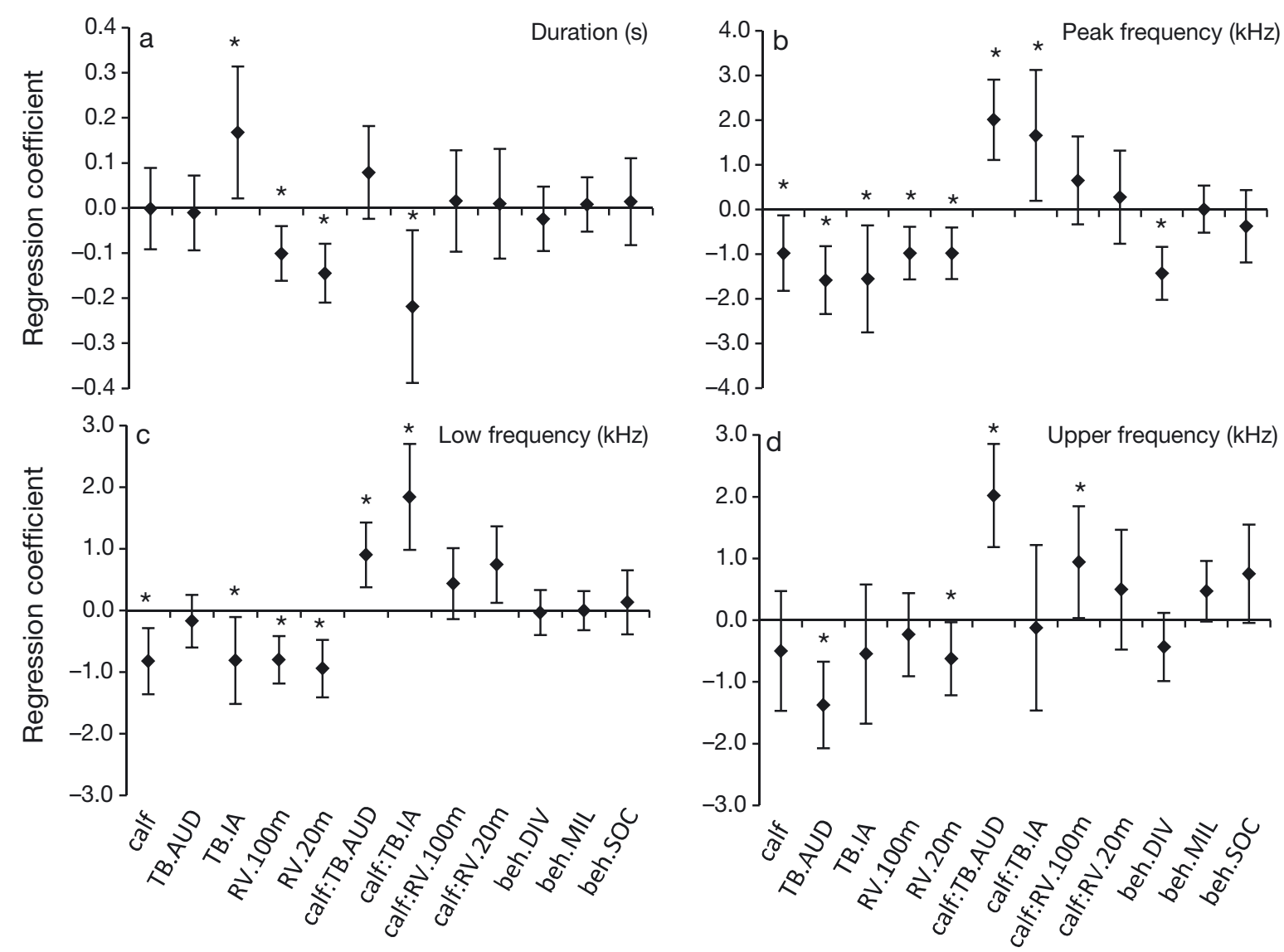

Fig. 5. Model-averaged estimates for the analyses of whistle parameters of bottlenose dolphins Tursiops truncatus in Doubtful Sound. Whistle parameters are (a) duration, (b) peak frequency, (c) lower frequency and (d) upper frequency. Points are regression coefficients; error bars are $95 \% \mathrm{CI}_{i}$ asterisks indicate significant effects. Reference categories are TB.NAUD, beh. travelling, no calves, RV.200m. Abbreviations are as follows: beh = behaviour state $(\mathrm{DIV}=$ diving, $\mathrm{MIL}=\mathrm{milling}, \mathrm{SOC}=$ socialising); $\mathrm{TB}=$ tour boat (NAUD = not audible, $\mathrm{AUD}=$ audible $<200 \mathrm{~m}$ from dolphins, $\mathrm{IA}=$ audible $<200 \mathrm{~m}$ from dolphins); $\mathrm{RV}=$ distance of research vessel from dolphins $(200,100$, or $20 \mathrm{~m})$; calf $=$ calves present

Although many cetacean studies have documented increased speeds and direction changes in response to the presence of boats (e.g. Nowacek et al. 2001, Williams et al. 2002, Lemon et al. 2006, Schaffar et al. 2013), no such changes were detected in this study. This could be related to tour boats in Doubtful Sound generally travelling at very slow speeds $(\bar{x}=2.9$ knots, $C V=1.1)$ while within $200 \mathrm{~m}$ of the dolphins. The level of boat intrusiveness and speed has been found to influence dolphin behaviour strongly (Lusseau 2003b, Timmel et al. 2008); perhaps the slow speeds we observed are low enough to avoid triggering the reactions found in populations elsewhere. 


\section{Effects of boats on dolphin communication}

Decreased whistle rates in groups without calves when boats were faster (i.e. louder) suggests that elevated vessel noise inhibits communication and/or increases its cost. When calves are present, however, there may be greater need to maintain or reestablish acoustic contact, despite potentially increased costs. Cohesion of groups with calves is reduced when tour boats are audible. Increased vocalisation rates in these groups during interactions and when boats were departing are therefore likely to reflect a re-establishment of cohesion between mother-calf pairs and/or with the rest of the group (Scarpaci et al. 2000, Van Parijs \& Corkeron 2001a). Additionally, the strong effect of boat speed on whistle rate suggests that noise is an important disturbance to communication, and that increased signal repetition may be used to compensate for masking at high noise levels. Consistent with other studies (e.g. Van Parijs \& Corkeron 2001b, Lemon et al. 2006), whistle rates were highest when dolphins were socialising.

We also observed modifications in whistle duration and frequency structure as a response to vessel noise, with different reactions depending on whether there were calves in the group. Due to spectral overlap, boat noise is likely to reduce the range at which dolphin whistles can be heard by conspecifics (Jensen et al. 2009). To increase communication range, dolphins may alter their vocalisations to avoid frequency bands of loudest ambient noise (see Au et al. 1974, 1985, for demonstration of this for sonar signals). In Doubtful Sound, calf presence strongly influenced the dolphins' responses. Groups with calves decreased the duration of their whistles and whistled at a higher pitch when tour boats were audible. We interpret this reaction as an attempt to increase signal detectability between mothers and their calves or among mother-calf pairs, by decreasing the spectral overlap with vessel noise, which is biased towards lower frequencies (S. Dawson et al. unpubl. data). Groups without calves had the opposite reaction, producing longer whistles of lower frequency when tour boats were audible, which may improve the likelihood of communication via increasing signal energy (via longer whistle duration). That groups without calves should shift to lower-frequency whistles is somewhat puzzling, since boat noise has higher sound pressure levels at low frequencies, and thus modifications to vocalisations by cetaceans in response to vessel noise would be expected to involve a shift to upper frequencies (e.g. Lesage et al. 1999, Parks et al. 2007, La Manna et al. 2013). Although it is not possible to determine the biological meaning of the observed changes, it is clear that the presence of calves is an important factor in the dolphins' acoustic reactions to boat noise, and that whistle modifications are likely to reflect a deviation from optimal communication conditions. These results hint that more research is needed to clarify the mechanisms by which vocal animals deal with anthropogenic noise in different social situations.

Few marine mammal studies have investigated modifications to vocalisations in response to vessel noise, but it seems evident that animals can adjust their calls when background noise increases - presumably to increase signal detectability or compensate for potential masking effects. Shifts in whistles to higher frequency bands due to increased boat noise (as observed in this study in groups with calves) have been measured in other bottlenose dolphin populations (La Manna et al. 2013) and in other cetacean species. Belugas Delphinapterus leucas, for example, produce calls of increased mean frequency when vessel noise is higher (Lesage et al. 1999), and North Atlantic right whales Eubalaena glacialis shift the frequency of their calls upwards to reduce interference with elevated low-frequency shipping noise (Parks et al. 2007). Increases in whistle duration (as observed in the present study in groups without calves) have also been reported as short-term (Tursiops truncatus; La Manna et al. 2013) and long-term (Orcinus orca; Foote et al. 2004) responses to elevated boat noise. Other animals that use sound for communication have also been shown to modify their calls to compensate for interference from background noise. In response to urban noise, for example, song-birds increase sound levels (Brumm \& Todt 2002), modify song amplitude (Brumm 2004) and sing at higher frequencies (Slabbekoorn \& Peet 2003).

One potential source of bias in the present study is that if vessel noise is loud enough, it may mask some vocalisations, resulting in underestimation of whistle rate when boats are present. The results from this study indicated an increase in whistle rate in some scenarios in which vessel noise was actually higher (i.e. during dolphin-boat interactions or at higher boat speeds, in the case of groups with calves). This suggests that masking effects of signals in the spectrograms were probably small and, in any case, that this error would result in underestimating the effect of vessels on the acoustic behaviour of dolphins. 


\section{Effects of the RV on movement patterns and acoustic behaviour}

Our study has shown that RV effects can be measured via a methodology centred on staged approaches. The RV affected the movement patterns of dolphins, especially group density and coordination, and different responses were observed, depending on the presence of calves. It is also worth noting that the dolphins' group cohesion varied depending on whether the RV was at an approaching or retreating stage of the SA. This could be driven by prolonged exposure time, or reflect behavioural differences between before and after the close-range stage. The meaning of observed changes in movement patterns is difficult to interpret, and it is not possible to discern whether these patterns reflect habituation to the RV. What is clear is that calf presence influences the way dolphin groups react to the $R V$, and that these effects justify the methodology and analytical approach adopted in this study.

In contrast to tour boats, the RV had no measureable effect on whistle rates, but did affect the properties of whistles during the close stages of the encounter. This suggests that even low noise levels can disturb the communication environment. The overall effect of the RV on the acoustic behaviour of dolphins was considerably smaller than that caused by tour boats.

Because tour boat interactions were relatively infrequent, we had a much larger sample size to investigate the effects of the RV than of the tour boats. This meant that statistical power to detect effects was much higher for the RV, and that small effects of the RV could be detected, while tour boat effects of the same or larger magnitude may not have been.

The methodology of this study aimed to be minimally intrusive. It required no physical contact with the dolphins and used a particularly quiet RV that, while with dolphins, was driven no faster than their travel speed. Even so, the research boat had some impact on the dolphins' movement patterns and whistle properties, highlighting the importance of accounting for the impact of the observing vessel in studies of cetacean behaviour.

\section{Conclusions and management implications}

The bottlenose dolphin population of Doubtful Sound has a history of low calf survival and rapid population decline (Currey et al. 2007, 2009a). Furthermore, there are profound differences between individual mothers with respect to the survival of their calves (Henderson et al. 2014). This population is therefore particularly vulnerable to anthropogenic impacts, which could affect pregnant females, mothers and dependent calves. We have shown that groups with mother-calf pairs are particularly sensitive to boat presence and noise. In addition, increased freshwater input from a hydroelectric power station may result in newborn calves being thermally compromised in winter and spring, when the tailrace water is cooler than the underlying water (Currey et al. 2009a). There is an obvious need for management to maximise protection of these demographic groups, highlighting the importance of ensuring a sustainable tourism industry in Doubtful Sound.

The biological implications and long-term consequences of the observed changes in behaviour cannot be estimated without knowing how they affect energetic budgets, stress levels and associated risks. Currently this is not possible. Without an understanding of long-term impacts, it is challenging to translate scientific findings into appropriate management recommendations (Seddon \& Ellenberg 2007). Even so, understanding the short-term effects of tourism, and what factors accentuate them, can help develop management strategies to mitigate potential impacts. The small size of the population, its endangered status and history of low calf survival (Currey et al. 2009a,b) argue for a precautionary approach to managing anthropogenic impacts.

The current code of management in Doubtful Sound stipulates that tour boats cannot approach dolphins to seek interactions, and areas designated as 'Dolphin Protection Zones' are restricted to vessel traffic. Such guidelines have resulted in a decrease in the frequency of dolphin-boat interactions (M. Guerra \& S. Dawson unpubl. data). Nevertheless, the influence of boat noise and speed on dolphins' reactions suggests that boat speed and noise minimisation should be included in management measures to mitigate vessel impacts.

Acknowledgements. We thank the New Zealand Department of Conservation (Fiordland District) for funding this study and for logistical support, in particular Richard Kinsey, Kath Blakemore and Dave Johnson. The New Zealand Whale and Dolphin Trust supplied our research vessel and all research equipment. We also thank the Fiordland Marine Mammal Levy Group, the University of Otago and the Deep Cove Outdoor Education Trust. We thank David Fletcher for statistical advice. This manuscript was improved by the comments of 2 anonymous reviewers. This study was carried out following the 'Marine Mammal Protection Regulations' (1992), which are pursuant to Section 28 of the New Zealand's 'Marine Mammals Protection Act' (1978), and under 
a research permit issued by the New Zealand Department of Conservation.

\section{LITERATURE CITED}

Agresti A (2002) Categorical data analysis, 2nd edn. Wiley, New York, NY

Akaike H (1973) Information theory and an extension of the maximum likelihood principle. In: Csáki F (ed) Proc 2nd Int Symp Information Theory. Akadémiai Kiadó, Budapest, p 267-281

Altmann J (1974) Observational study of behaviour: sampling methods. Behaviour 49:227-267

Anderson DR (2008) Model based inference in the life sciences: a primer on evidence. Springer, New York, NY

> Arveson PT, Vendittis DJ (2000) Radiated noise characteristics of a modern cargo ship. J Acoust Soc Am 107: 118-129

Au WWL (1993) The sonar of dolphins. Springer, New York, NY

> Au WWL, Floyd RW, Penner RH, Murchison AE (1974) Measurement of echolocation signals of the Atlantic bottlenose dolphin, Tursiops truncatus Montagu, in open waters. J Acoust Soc Am 56:1280-1290

Au WWL, Carder DA, Penner RH, Scronce BL (1985) Demonstration of adaptation in beluga whale echolocation signals. J Acoust Soc Am 77:726-730

Barlow J, Rankin S, Dawson S (2008) A guide to constructing hydrophones and hydrophone arrays for monitoring marine mammal vocalization. NOAA Tech Memo NMFS 417, February 2008

- Bejder L, Samuels A, Whitehead H, Gales N and others (2006) Decline in relative abundance of bottlenose dolphins exposed to long-term disturbance. Conserv Biol 20: 1791-1798

> Brumm H (2004) The impact of environmental noise on song amplitude in a territorial bird. J Anim Ecol 73:434-440

Brumm H, Todt D (2002) Noise-dependent song amplitude regulation in a territorial songbird. Anim Behav 63: 891-897

Buckstaff KC (2004) Effects of watercraft noise on the acoustic behavior of bottlenose dolphins, Tursiops truncatus, in Sarasota Bay, Florida. Mar Mamm Sci 20:709-725

Burnham KP, Anderson DR (2002) Model selection and multimodel inference: a practical information-theoretic approach. Springer, New York, NY

Burnham KP, Anderson DR, Huyvaert KP (2011) AIC model selection and multimodel inference in behavioural ecology: some background, observations and comparisons. Behav Ecol Sociobiol 65:23-35

Caldwell MC, Caldwell DK, Tyack PL (1990) Review of the signature whistle hypothesis for the Atlantic bottlenose dolphin. In: Leatherwood S, Reeves RR (eds) The bottlenose dolphin. Academic Press, San Diego, CA, p 199-234

> Christiansen F, Lusseau D, Stensland E, Berggren P (2010) Effects of tourist boats on the behaviour of Indo-Pacific bottlenose dolphins off the south coast of Zanzibar. Endang Species Res 11:91-99

Currey RJC, Dawson SM, Slooten E (2007) New abundance estimates suggest Doubtful Sound bottlenose dolphins are declining. Pac Conserv Biol 13:265-273

Currey R, Dawson SM, Slooten E, Schneider K and others (2009a) Survival rates for a declining population of bottlenose dolphins in Doubtful Sound, New Zealand: an information theoretic approach to assessing the role of human impacts. Aquat Conserv 19:658-670

> Currey RJC, Dawson SM, Slooten E (2009b) An approach for regional threat assessment under IUCN Red List criteria that is robust to uncertainty: the Fiordland bottlenose dolphins are critically endangered. Biol Conserv 142: 1570-1579

- Foote AD, Osborne RW, Hoelzel AR (2004) Whale-call response to masking boat noise. Nature 428:910

Garamszegi LZ (2011) Information-theoretic approaches to statistical analysis in behavioural ecology: an introduction. Behav Ecol Sociobiol 65:1-11

Gelman A (2008) Scaling regression inputs by dividing by two standard deviations. Stat Med 27:2865-2873

> Grueber CE, Nagakawa S, Laws RJ, Jamieson IG (2011) Multimodel inference in ecology and evolution: challenges and solutions. J Evol Biol 24:699-711

> Henderson SD, Dawson SM, Rayment WJ, Currey RJC (2013) Are the 'resident' dolphins of Doubtful Sound becoming less resident? Endang Species Res 20:99-107

Henderson SD, Dawson SM, Currey RJ, Lusseau D, Schneider K (2014) Reproduction, birth seasonality and calf survival of bottlenose dolphins in Doubtful Sound, New Zealand. Mar Mamm Sci (in press), doi:10.1111/mms. 12109

Hernandez EN, Solangi M, Kuczaj SA II (2010) Time and frequency parameters of bottlenose dolphin whistles as predictors of surface behaviour in the Mississippi Sound. J Acoust Soc Am 127:3232-3238

Herzing DL (1996) Vocalizations and associated underwater behavior of free-ranging Atlantic spotted dolphins, Stenella frontalis, and bottlenose dolphins, Tursiops truncatus. Aquat Mamm 22:61-79

Higham JES, Lück M (2007) In search of scientific approaches to sustainability. In: Higham J, Lück L (eds) Marine wildlife and tourism management: insights from the natural and social sciences. CABI, Wallingford, p 1-16

> Janik VM, Slater PJ (1998) Context-specific use suggests that bottlenose dolphin signature whistles are cohesion calls. Anim Behav 56:829-838

> Jensen FH, Bejder L, Wahlberg J, Aguilar-Soto N, Johnson M, Madsen PT (2009) Vessel noise effects on delphinid communication. Mar Ecol Prog Ser 395:161-175

Johnson JB, Omland KS (2004) Model selection in ecology and evolution. Trends Ecol Evol 19:101-108

La Manna G, Manghi M, Pavan G, Lo Mascolo F, Sarà G (2013) Behavioural strategy of common bottlenose dolphins (Tursiops truncatus) in response to different kinds of boats in the water of Lampedusa Island (Italy). Aquat Conserv 23:745-757

> Lemon M, Lynch TP, Cato DH, Harcourt RG (2006) Response of travelling bottlenose dolphins (Tursiops aduncus) to experimental approaches by a powerboat in Jervis Bay, New South Wales, Australia. Biol Conserv 127:363-372

> Lesage V, Barrette C, Kingsley MCS, Sjare B (1999) The effect of vessel noise on the vocal behaviour of belugas in the St. Lawrence River estuary, Canada. Mar Mamm Sci 15:65-84

Lundquist D, Gemmell NJ, Würsig B (2012) Behavioural responses of dusky dolphin groups (Lagenorhynchus obscurus) to tour vessels off Kaikoura, New Zealand. PLoS ONE 7:e41969

Lusseau D (2003a) Effects of tour boats on the behaviour of bottlenose dolphins: using Markov chains to model anthropogenic impacts. Conserv Biol 17:1785-1793 
Lusseau D (2003b) Male and female bottlenose dolphins Tursiops spp. have different strategies to avoid interactions with tour boats in Doubtful Sound, New Zealand. Mar Ecol Prog Ser 257:267-274

Lusseau D (2005) Residency pattern of bottlenose dolphins Tursiops spp. in Milford Sound, New Zealand, is related to boat traffic. Mar Ecol Prog Ser 295:265-272

Lusseau D (2006) The short-term behavioural reactions of bottlenose dolphins to interactions with boats in Doubtful Sound, New Zealand. Mar Mamm Sci 22:802-818

McCulloch CE, Searle SH, Neuhaus JM (2008) Generalized, linear and mixed models, 2nd edn. Wiley, New York, NY

> Miller LJ, Solangi M, Kuczaj SA II (2008) Immediate response of Atlantic bottlenose dolphins to high-speed personal watercraft in the Mississippi Sound. J Mar Biol Assoc UK 88:1139-1143

Morrison ML, Block WM, Strickland MD, Kendall WL (2001) Wildlife study design. Springer, New York, NY

Nakagawa S, Freckleton RP (2011) Model averaging, missing data and multiple imputation: a case study for behavioural ecology. Behav Ecol Sociobiol 65:103-116

> Nowacek SM, Wells RS, Solow AR (2001) Short-term effects of boat traffic on bottlenose dolphins, Tursiops truncatus, in Sarasota Bay, Florida. Mar Mamm Sci 17: 673-688

Parks SE, Clark CW, Tyack P (2007) Short- and long-term changes in right whale calling behavior: the potential effects of noise on acoustic communication. J Acoust Soc Am 122:3725-3731

R Core Team (2012) R: a language and environment for statistical computing. R Foundation for Statistical Computing, Vienna. www.R-project.org/

Richards SA, Whittingham MJ, Stephens PA (2011) Model selection and model averaging in behavioural ecology: the utility of the IT-AIC framework. Behav Ecol Sociobiol 65:77-89

Richardson WJ, Malme CI (1995) Zones of noise influence. In: Richardson WJ, Greene Jr CR, Malme CI, Thomson DH (eds) Marine mammals and noise. Academic Press, San Diego, CA, p 325-386

> Richter C, Dawson S, Slooten E (2006) Impacts of commercial whale watching on male sperm whales at Kaikoura, New Zealand. Mar Mamm Sci 22:46-63

Scarpaci C, Bigger SW, Corkeron PJ, Nugegoda D (2000) Bottlenose dolphins (Tursiops truncatus) increase whistling in the presence of 'swim-with-dolphin' tour operations. J Cetacean Res Manag 2:183-185

Schaffar A, Madon B, Garrigue C, Constantine R (2013) Behavioural effects of whale-watching activities on an Endangered population of humpback whales wintering in New Caledonia. Endang Species Res 19:245-254

Scheifele PM, Andrew S, Cooper RA, Darre M, Musiek FE, Max L (2005) Indication of a Lombard vocal response in the St. Lawrence River beluga. J Acoust Soc Am 117: 1486-1492

Schneider K (1999) Behaviour and ecology of bottlenose dolphins in Doubtful Sound, Fiordland, New Zealand. $\mathrm{PhD}$ dissertation, University of Otago, Dunedin
Schneider K, Baird RW, Dawson S, Visser I, Childerhouse S (1998) Reactions of bottlenose dolphins to tagging attempts using a remotely-deployed suction-cup tag. Mar Mamm Sci 14:316-324

Seddon PJ, Ellenberg U (2007) Effects of human disturbance on penguins: the need for site- and species-specific visitor management guidelines. In: Higham J, Lück L (eds) Marine wildlife and tourism management: insights from the natural and social sciences. CABI, Wallingford, p 163-181

Slabbekoorn H, Peet M (2003) Ecology: birds sing at a higher pitch in urban noise. Nature 424:267

> Smolker RA, Mann J, Smuts BB (1993) Use of signature whistles during separations and reunions by wild bottlenose dolphin mothers and infants. Behav Ecol Sociobiol 33:393-402

Stamation KA, Croft DB, Shaughnessy PD, Waples KA, Briggs SV (2010) Behavioural responses of humpback whales (Megaptera novaeangliae) to whale-watching vessels on the southeastern coast of Australia. Mar Mamm Sci 26:98-122

> Steckenreuter A, Möller L, Harcourt R (2012) How does Australia's largest dolphin-watching industry affect the behaviour of a small and resident population of IndoPacific bottlenose dolphins? J Environ Manage 97:14-21

Stensland E, Berggren P (2007) Behavioural changes in female Indo-Pacific bottlenose dolphins in response to boat-based tourism. Mar Ecol Prog Ser 332:225-234

Symonds RE, Moussalli A (2011) A brief guide to model selection, multimodel inference and model averaging in behavioural ecology using Akaike's information criterion. Behav Ecol Sociobiol 65:13-21

Timmel G, Courbis S, Sargeant-Green H, Markowtiz H (2008) Effects of human traffic on the movement patterns of Hawaiian spinner dolphins (Stenella longirostris) in Kealakekula Bay, Hawaii. Aquat Mamm 34:402-411

Tyack PL, Clark CW (2000) Communication and acoustic behaviour of dolphins and whales. In: Au WWL, Popper AN, Fay RR (eds) Hearing by whales and dolphins. Springer, New York, NY, p 156-224

Van Parijs SM, Corkeron PJ (2001a) Boat traffic affects the acoustic behaviour of Pacific humpback dolphins, Sousa chinensis. J Mar Biol Assoc UK 81:533-538

Van Parijs SM, Corkeron PJ (2001b) Vocalizations and behaviour of Pacific humpback dolphins, Sousa chinensis. Ethology 107:701-716

Wells RS, Scott MD (1999) Bottlenose dolphin Tursiops truncatus (Montagu, 1821). In: Ridgway SH, Harrison R (eds) Handbook of marine mammals, Vol 6. The second book of dolphins and porpoises. Academic Press, San Diego, CA, p 137-182

Williams R, Trites AW, Bain DE (2002) Behavioural responses of killer whales (Orcinus orca) to whale-watching boats: opportunistic observations and experimental approaches. J Zool (Lond) 256:255-270

Williams R, Lusseau D, Hammond PS (2006) Estimating relative energetic costs of human disturbance to killer whales (Orcinus orca). Biol Conserv 133:301-311

Submitted: October 23, 2013; Accepted: February 27, 2013 Proofs received from author(s): May 25, 2014
Editorial responsibility: Philip Stephens, Durham, UK 